\title{
ESSENTIAL OILS AND METHYLGLYOXAL: A POSSIBLE ALTERNATIVE TREATMENT FOR ANTIBIOTIC RESISTANT BACTERIAL INFECTIONS
}

\author{
ERIN CIESLAK ${ }^{1 *}$, JAMES P. MACK ${ }^{1}$, ALBERT ROJTMAN ${ }^{2}$ \\ ${ }^{1}$ Department of Biology, Monmouth University, West Long Branch, NJ, USA, 2Department of Pathology, Meridian Health, Jersey Shore \\ University Medical Center, Neptune, NJ, USA \\ Email: mack@monmouth.edu
}

Received: 15 Apr 2016 Revised and Accepted: 22 Jul 2016

\begin{abstract}
Objective: Essential oils are of significant interest in today's world of healthcare because these compounds have a variety of medicinal properties. In this study, we evaluated the in vitro antibiotic role of essential oils as a possible alternative treatment in combatting Methicillin-resistant
\end{abstract} Staphylococcus aureus (MRSA).

Methods: In conjunction with carrier oils, three essential oils (cassia, cinnamon bark, and thyme), as well as methylglyoxal were tested on MRSA using the Kirby-Bauer disc diffusion method.

Results: The minimum inhibitory concentration of each tested essential oil and methylglyoxal in carrier oil was determined to be $25 \%$ essential oil and $75 \%$ carrier oil mixture. This concentration worked much more effectively than the standard antibiotic, vancomycin, which is currently used to treat MRSA infections.

Conclusion: Antibacterial emollients made from naturally occurring products like essential oils can be cost-effective alternatives to antibiotics. The results of this research show that these emollients are more effective against MRSA than standard antibiotics in cell culture.

Keywords: Methicillin-resistant Staphylococcus aureus, Essential oils, Cassia, Cinnamon bark, Thyme, Methylglyoxal, Antibiotic resistance

(C) 2016 The Authors. Published by Innovare Academic Sciences Pvt Ltd. This is an open access article under the CC BY license (http://creativecommons. org/licenses/by/4. 0/)

DOI: http://dx.doi.org/10.22159/ijpps.2016.v8i9.12242

\section{INTRODUCTION}

Antibiotics have long been the "go-to" treatment for pathogenic bacterial infections [1]. Common antibiotics, such as penicillin and methicillin, have been used since the mid-1900's. These antibiotics, once effective medications for treating bacterial infections, have rapidly become less useful due to the highly adaptive genomes of pathogenic bacteria [2]. Bacterial genomes contain plasmids, which are small, circular, extracellular pieces of DNA that allow the bacterium to evolve quickly and adapt to its environment [3]. As antibiotics were being used, and oftentimes, misused, many bacterial species developed a resistance gene against the antibiotic within its plasmid DNA [4].

Antibiotic resistant bacteria are receiving national attention in the United States. The White House and the CDC are working tirelessly to find ways to help prevent the antibiotic resistant bacteria pandemic from worsening by releasing an annual update on the matter to the public. In the latest 2014 update, the White House released this statistic: "[The CDC estimates that] annually at least two million illnesses and 23,000 deaths are caused by antibiotic-resistant bacteria in the United States alone" [5]. Scientists have been researching for years for effective ways to treat such infections like MRSA that are resistant to common antibiotics, resulting in the creation of newer classes of FDA-approved antibiotics which are costly and possibly short-lived in efficacy as it has been seen with earlier antibiotics.

Antibiotics can kill bacteria, both helpful and pathogenic, within an organism. Broad-spectrum antibiotics have severe side effects in many patients who are taking them. These side effects include nausea, vomiting, diarrhea, numbness, urinary retention, and even the possibility of becoming more susceptible to other infections due to the fact that the body's microbiota (like E. coli, Lactobacillus species) are being destroyed along with the pathogenic bacteria. With options growing thin and unpleasant, some scientists have turned towards natural products, such as essential oils, for therapy.

Plants and their derivatives have been used for medicinal purposes as far back as the Egyptian civilizations in 2800 BC [6]. Essential oils are chemical compounds that can be hydrocarbons or oxygenated compounds like esters, aldehydes, alcohols, and phenols that are derived from plants. For therapeutic purposes, essential oils are usually diluted in a carrier before being applied to the skin to prevent irritation [6]. In this study, the essential oils cassia, cinnamon bark, and thyme as well as a key ingredient in Australia's popular Manuka honey, methylglyoxal, were being tested for efficacy as emollients with several carrier oils in treating MRSA infections.

These essential oil compounds showed promise against antibiotic resistant bacteria in previous studies conducted at Monmouth University [7-8]. These studies showed that essential oil emollients could be excellent alternative treatments for topical infections caused by antibiotic-resistant bacteria.

\section{MATERIALS AND METHODS}

\section{Bacterial strains and growth conditions}

MRSA samples were supplied by Dr. Albert Rojtman, Chief of Clinical Microbiology at Jersey Shore University Medical Center in Neptune, NJ, USA. The anonymous samples were originally cultured on blood agar plates. For experimentation, the bacteria were grown under aerobic conditions on Mueller Hinton II agar media over a 24 hour incubation period at $37^{\circ} \mathrm{C}$.

\section{Obtaining essential oils}

Methylglyoxal ( $40 \%$ in $\mathrm{H}_{2} \mathrm{O}$ ) was obtained by mail order from Sigma Aldrich ${ }^{\circledR}$ of St. Louis, MO, USA. Cassia, cinnamon bark, and thyme were obtained by mail order from dōTERRA Essential Oils® of Pleasant Grove, UT, USA.

\section{Obtaining carrier oils}

Jojoba oil was obtained by mail order from Sigma Aldrich ${ }^{\circledR}$ of St. Louis, MO, USA. Coconut oil was obtained by mail order from dōTERRA Essential Oils ${ }^{\circledR}$ of Pleasant Grove, UT, USA. Liquid Lanolin was obtained by mail order from Now ${ }^{\circledR}$ Solutions of Bloomingdale, IL, USA. Olive oil (Filippo Berio ${ }^{\circledR}$ ) was purchased at the local supermarket. All four carrier oils are safe for use on skin. 


\section{Standard antibiotics utilized}

Vancomycin susceptibility test discs $(30 \mu \mathrm{g})$ and rifampin susceptibility test discs (5 $\mu \mathrm{g})$ were obtained by mail order from Becton, Dickinson and Company of Franklin Lakes, NJ, USA.

\section{Preparation of mueller hinton II agar medium}

Mueller Hinton II agar was purchased by mail order from Becton, Dickinson and Company of Franklin Lakes, NJ, USA. Mueller Hinton II agar was chosen as a nutritive source for growing the MRSA bacteria as well as its suitability for performing susceptibility testing. The media was prepared as per manufacturer's instructions under sterile conditions. Prepared media plates were stored at $4{ }^{\circ} \mathrm{C}$ until ready for use.

\section{Kirby-bauer disc diffusion}

A single MRSA colony from the blood agar plate provided by JSUMC was reconstituted in tryptic soy nutrient broth to match a 0.5 McFarland standard $1 \times 10^{8}$ colony forming unit per milliliter ( $\mathrm{CFU} / \mathrm{ml}$ ) volume. The broth culture was then swabbed onto the Mueller Hinton II agar plates.

Sterile blank $6 \mathrm{~mm}$ paper discs were placed in the center of each swabbed plate. A volume of $5 \mu \mathrm{l}$ of each emollient was pipetted onto the blank disc. Vancomycin $(30 \mu \mathrm{g})$ and rifampin $(5 \mu \mathrm{g})$ antibiotic susceptibility test discs were also placed on swabbed plates to act as controls. After a 24 hour incubation period at $37^{\circ} \mathrm{C}$, the diameters of zones of inhibition around each disc were measured in millimeters [9].

The experiments were performed in triplicate and the zone of inhibition measurements were averaged to yield a mean zone of inhibition.

\section{RESULTS AND DISCUSSION}

Antibiotic discs of both vancomycin $(30 \mu \mathrm{g})$ and rifampin $(5 \mu \mathrm{g})$ were both tested against the MRSA in every experiment. Vancomycin averaged a zone of inhibition of $19 \mathrm{~mm}$ and rifampin averaged a zone of inhibition of $36 \mathrm{~mm}$ (table 1). Rifampin is used as an adjuvant only in very severe cases of MRSA when biofilm formation is suspected, so vancomycin is still the current standard of care [10]. However, it is apparent that vancomycin is losing its effectiveness against MRSA because a growing number of MRSA infections are showing antibiotic treatment failures.

Table 1: Mean diameter of zone of inhibition of standard antibiotics used to treat MRSA

\begin{tabular}{ll}
\hline Standard antibiotic & $\begin{array}{l}\text { Mean diameter of zone of } \\
\text { inhibition (mm) }\end{array}$ \\
\hline Vancomycin & 19 \\
Rifampin & 36 \\
\hline
\end{tabular}

In order to effectively determine the minimum inhibitory concentration (MIC) of the essential oils, the experiments began by testing a concentration of $100 \%$ of each carrier oil against the MRSA to determine that the carriers chosen did not show any antibacterial effect of their own against the MRSA. A volume of $5 \mu$ of fractionated coconut oil, jojoba oil, lanolin oil, and olive oil was pipetted onto a sterile blank paper disc and tested in triplicate against the MRSA. All proved to have no antibacterial properties because there was no zone of inhibition surrounding each carrier oil disc in every trial (table 2).

Table 2: Mean diameter of zone of inhibition of carrier oils at $100 \%$ concentration used against MRSA

\begin{tabular}{ll}
\hline Essential oil & $\begin{array}{l}\text { Mean diameter of zone of inhibition } \\
(\mathbf{m m})\end{array}$ \\
\hline Fractionated coconut & 0.0 \\
oil & \\
Jojoba oil & 0.0 \\
Lanolin oil & 0.0 \\
Olive oil & 0.0 \\
\hline
\end{tabular}

Once the carrier oils were proved to have no bactericidal properties, $5 \mu \mathrm{l}$ of the essential oils were tested at $100 \%$ concentration to show that each essential oil chosen did, in fact, show antibacterial properties specific to MRSA. Each of the three essential oils, cassia, cinnamon bark, and thyme, as well as methylglyoxal, the main component of Australia's popular Manuka honey, all formed large zones on inhibition that were larger than the zones of inhibition of both tested antibiotics (table 3).

Table 3: Mean diameter of zone of inhibition of essential oils at $100 \%$ concentration used against MRSA

\begin{tabular}{ll}
\hline Essential oil & Mean diameter of zone of inhibition (mm) \\
\hline Cassia & 40.3 \\
Cinnamon bark & 38.7 \\
Methylglyoxal & 43.3 \\
Thyme & 37.3 \\
\hline
\end{tabular}

The essential oil concentration was halved to $50 \%$ for the first dilution trial. The remaining $50 \%$ of the volume contained one of the four carrier oils. Each essential oil was tested in combination with each of the four carriers against the MRSA. Dilution was necessary because although in this experiment emollients were not being tested on skin, essential oils at their full concentration are normally known to be very irritant on the skin and would not be a feasible treatment on an open wound, like a MRSA infection.

Table 4a: Mean diameter of zone of inhibition of $50 \%$ essential oil and $50 \%$ carrier oil emollient against MRSA

\begin{tabular}{lll}
\hline Essential oil & Carrier oil & Mean diameter of zone of inhibition (mm) \\
\hline Cassia & Coconut & 36.7 \\
& Jojoba & 44 \\
& Lanolin & 35 \\
Cinnamon bark & Olive & 38.3 \\
& Coconut & 31.3 \\
& Jojoba & 40.3 \\
Lanolin & 33.7 \\
Methylglyoxal & Olive & 36.3 \\
& Coconut & 41.7 \\
& Jojoba & 43 \\
Thyme & Lanolin & 38 \\
& Olive & 42.3 \\
& Coconut & 7.7 \\
& Jojoba & 14 \\
& Lanolin & 16.7 \\
\hline
\end{tabular}


Hence, the goal of finding the lowest dilution concentration of essential oil emollient that would still be deemed more effective than the standard antibiotic. At a 50\% dilution, both cassia, cinnamon bark, and methylglyoxal all worked significantly better than vancomycin based on measured zone of inhibition. Of those three, cassia and methylglyoxal worked the best, working as well or better than even the strong rifampin antibiotic. Thyme, an essential oil that worked well on its own, did not work well in conjunction with carrier oils (table 4a) and therefore was excluded from further dilution trials.
Cassia, cinnamon bark, and methylglyoxal were chosen to continue the dilution trials. The essential oil concentration was halved once again to $25 \%$. The remaining $75 \%$ of the emollient consisted of a carrier oil. Cassia, cinnamon, and methylglyoxal mixed with lanolin showed the weakest results. Although the results for lanolin carrier oil emollients were less effective overall than rifampin, this emollient still worked better than vancomycin. The strongest results were from cassia-jojoba oil, cassia-olive oil, methylglyoxal-olive oil, and methylglyoxal-coconut oil emollients, all of which continued to work more effectively than even rifampin (table $4 \mathrm{~b}$ ).

Table 4b: Mean diameter of zone of inhibition of 25\% essential oil and $75 \%$ carrier oil emollient against MRSA

\begin{tabular}{lll}
\hline Essential oil & Carrier oil & Mean diameter of zone of inhibition (mm) \\
\hline Cassia & Coconut & 32 \\
& Jojoba & 39.7 \\
& Lanolin & 35.7 \\
Cinnamon bark & Olive & 39.3 \\
& Coconut & 25.7 \\
& Jojoba & 29.7 \\
Lethylglyoxal & Lanolin & 25.3 \\
& Olive & 31.7 \\
& Coconut & 39 \\
& Jojoba & 35.3 \\
& Lanolin & 31 \\
\hline
\end{tabular}

In a second trial, the essential oil concentration was halved to $12.5 \%$ with the remaining $87.5 \%$ as a carrier oil. In this trial, the results were clearly disappointing. The cassia and cinnamon bark emollients worked about as effectively as vancomycin. Methylglyoxal still had a slight advantage over vancomycin, but none of the emollients were nearly as effective as rifampin (table $4 \mathrm{c}$ ).

Table 4c: Mean diameter of zone of inhibition of $12.5 \%$ essential oil and $87.5 \%$ carrier oil emollient against MRSA

\begin{tabular}{lll}
\hline Essential oil & Carrier oil & Mean diameter of zone of inhibition (mm) \\
\hline Cassia & Coconut & 20.3 \\
& Jojoba & 23.6 \\
Lanolin & 20 \\
Cinnamon bark & Olive & 20.3 \\
& Coconut & 13 \\
& Jojoba & 22.6 \\
Lethylglyoxal & Lanolin & 19.3 \\
& Olive & 18 \\
& Coconut & 27.3 \\
& Jojoba & 29 \\
& Lanolin & 21 \\
& Olive & 24.3 \\
\hline
\end{tabular}

At $25 \%$ dilution, all of the emollients worked significantly better than the vancomycin antibiotic. Several of the emollients at this concentration continued to exceed the results of rifampin. The results from the lowest dilution concentration (12.5\%) were unremarkable. Of the $25 \%$ dilutions, four had results that particularly stood out: cassia-jojoba oil, cassia-olive oil, methylglyoxal-olive oil, and methylglyoxal-coconut oil. All four of these emollients surpassed not only the vancomycin standard but also the rifampin antibiotic (fig. 1). Thus, the MIC of these essential oils were concluded to be $25 \%$.

The structures of methylglyoxal and cinnamaldehyde, (which is the main active ingredient that makes up $75-90 \%$ of cassia), contain aldehyde structures (fig. 2a, 2b). Aldehydes have been known to confer antimicrobial activity and have been an important component of laboratory disinfectants for years because of their ability to quickly and effectively kill pathogenic bacteria. Aldehydes act by inhibiting and preventing peptide and protein synthesis, and a bacterial cell that cannot make more proteins cannot persist [11]. The fact that these two essential oils contain aldehyde structures may help explain their antibacterial activity.

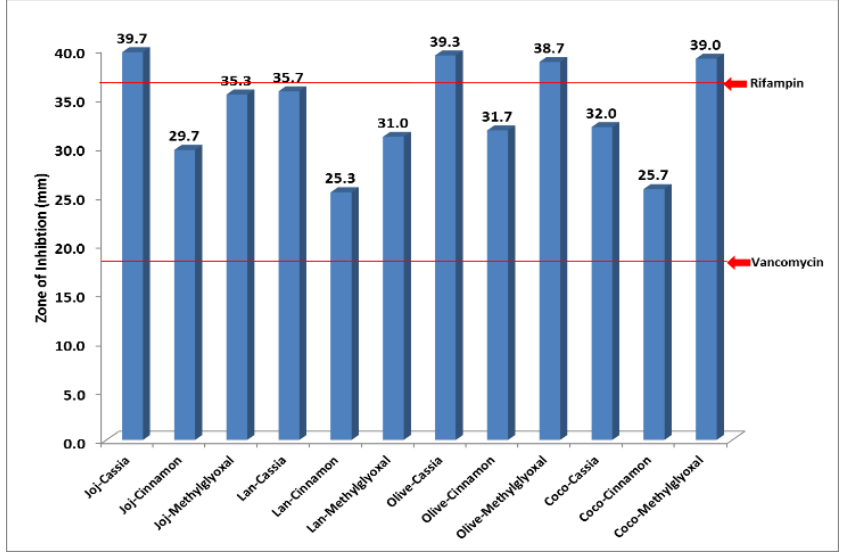

Fig. 1: Zone of inhibition (mm) plotted against $25 \%$ essential oil, $75 \%$ carrier oil emollients with reference to standard antibiotics 


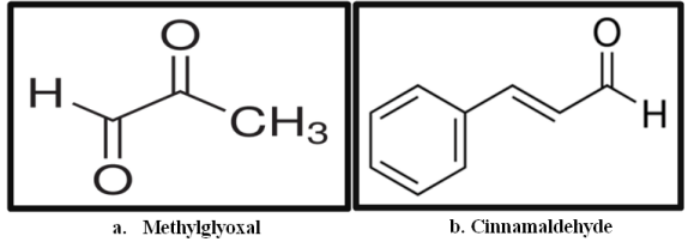

Fig. 2a-b: Structures of methylglyoxal, cinnamaldehyde (the main active ingredient in both cassia and cinnamon bark), respectively

\section{CONCLUSION}

Antibacterial emollients made from naturally occurring products like essential oils can be cost-effective alternatives to antibiotics. As a natural product that would be used on the skin, it could also potentially prevent the unpleasant side effects that go along with taking traditional antibiotics. This can also provide a possible alternative for those who prefer more natural methods of treatment, and for underserved populations that do not have access to or cannot afford other means of care. Cassia and methylglyoxal, have proven themselves in this study to have strong bactericidal properties at concentrations as low as $25 \%$ in carrier oil emollients, working even better than the current standard of care, vancomycin.

\section{ACKNOWLEDGEMENT}

We wish to thank the Summer Research Program and the Monmouth University Grant-in-Aid for Creativity for providing the funds to make this project possible. We wish to thank Dr. Albert Rojtman of Jersey Shore University Medical Center for his collaboration. We wish to thank Dr. Datta Naik for his contributions. We also thank Mr. Kevin Young of dōTERRA Essential Oils for his support.

\section{CONFLICTS OF INTERESTS}

Declared none

\section{REFERENCES}

1. Spellberg B, Bartlett J, Gilbert D. The future of antibiotics and resistance. N Engl J Med 2013;368:299-302.
2. Davies J, Davies D. Origins and evolution of antibiotic resistance. Microbiol Mol Biol Rev 2010;74:417-33.

3. Cui L, Iwamoto A, Lian JQ, Neoh HM, Maruyama T, Horikawa Y, et al. Novel mechanism of antibiotic resistance originating in vancomycin-intermediate Staphylococcus aureus. Antimicrob Agents Chemother 2006;50:428-38.

4. Amoako D, Bester L, Somboro A, Baijnath S, Govind CN, Essack SY. Plasmid-mediated resistance and virulence mechanisms in the private health sector in Kwa Zulu-Natal, South Africa: an investigation of methicillin-resistant Staphylococcus aureus (MRSA) clinical isolates collected during a three-month period. Int J Infect Dis 2016;46:38-41.

5. The White House. National Strategy for Combating AntibioticResistant Bacteria. Washington DC. The Center for Disease Control; 2014.

6. Lawless, Julia. The illustrated encyclopedia of essential oils: The complete guide to the use of oils in aromatherapy and herbalism. New York: Element Books Limited; 1995.

7. Sharma P, Mack J, Rojtman A. Ten highly effective essential oils inhibit the growth of Methicillin-Resistant Staphylococcus aureus (MRSA) and Methicillin Sensitive Staphylococcus aureus (MSSA). Int J Pharm Pharm Sci 2013;5:52-4.

8. Qureshi W, Palayekar V, Dayan E, Mack J, Rojtman A. Combating the antibiotic resistance threat. Int J Pharm Pharm Sci 2015; 7:68-72.

9. Bauer AW, Kirby WM, Sherris JC, Turck M. Antibiotic susceptibility testing by a standardized single disk method. Am J Clin Pathol 1966;45:493-6.

10. Liu C, Bayer A, Cosgrove SE, Daum RS, Fridkin SK, Gorwitz RJ, et al. Clinical practice guidelines by the Infectious Diseases Society of America for the treatment of methicillin-resistant Staphylococcus aureus infections in adults and children. Clin Infect Dis 2011;52:1-38.

11. Rutala W, Weber D. Guideline for disinfection and sterilization in healthcare facilities. Chapel Hill (NC): The Center for Disease Control; 2008.

\section{How to cite this article}

- $\quad$ Erin Cieslak, James P. Mack, Albert Rojtman. Essential oils and methylglyoxal: a possible alternative treatment for antibioticresistant bacterial infections. Int $\mathrm{J}$ Pharm Pharm Sci 2016;8(9):107-110. 